\title{
A Cognitive-Oriented Exploration of the Development of Translation Competence: A Case Study of Iranian Translation Learners
}

\author{
MUSTAFA KOMEILI \\ Faculty of Foreign Languages \\ University of Isfahan, Isfahan, Iran \\ AZIZOLLAH DABAGHI (Corresponding author) \\ Faculty of Foreign Languages \\ University of Isfahan, Isfahan, Iran \\ azizollahd@hotmail.com \\ HOSSEIN BARATI \\ Faculty of Foreign Languages \\ University of Isfahan, Isfahan, Iran
}

\begin{abstract}
This is a report on a qualitative research in relation to the development of translation competence (TC) in academia. The study aimed to map out the cognitive processes involved in problem-solving and provide a picture of the development of strategic TC and translation-notion in translation learners. A group of 20 Iranian students volunteered to take part in a think-aloud study. The participants were divided into four groups of G1 (pretranslational), G3 (early translational), G5 and G7 (translational), based on the number of semesters of language and translation training they had received. The ecological validity was established by availing the participants of any sources of documentation they preferred to use. The verbalisations of the participants were recorded and then transcribed into think-aloud protocols (TAPS). The analysis of TAPs revealed that students activated various configurations of decision-making processes and resourcing methods, and exhibit different conceptions of the notion-of-translation at different stages of TC development. The study also showed that the portrait of TC development featured strong reliance on automatised cognitive processes at pre-translational stage and increased evaluative processes, coupled with higher chances of success, at translational stage. The findings proved that the development of TC did not follow an incremental trajectory. They further indicated that the translation programmes as offered in universities tend to boost evaluative reflections on and conscious awareness of the translation process at the cost of decreasing the unconscious automatised processes. This suggests that from a process-oriented perspective, translation programmes do not seem to prepare the learners for translation-market requirements.
\end{abstract}

Keywords: translation; competence development; cognitive analysis; decision-making processes; Iranian learners

\section{INTRODUCTION}

One of the more recent areas of research in translation studies is concerned with attempts to conceptualise and further develop theoretical and practical grounds for training translators, developing teaching materials and testing translation performance, both within academic circumstances and the ever-expanding translation market (Beeby, et al, 2011; Dimitrova, 2005; Hurtado Albir, 2017; PACTE, 2000, 2002, 2003, 2005, 2008, 2009; Prassl, 2010; Schäffner \& Adab, 2000). Central to all these activities is the basic concept of translation competence; what it is and what it incorporates as its constituent elements; how it works and develops among translation trainees; what cognitive and mental processes and mechanisms inform it and so forth (Göpferich, 2015; Lörscher, 2012; Pym, 2003). 
Attempts that have so far been made toward delineating this process can be summarised into three main lines of thought: linguistic, cognitive, and didactic.

The linguistic perspective has a long tradition and involves the lion's share of scholarly discussions on translation. The cognitive perspective, informed by insights from cognitive linguistics and cognitive, social and communicative theories, although enjoys a relatively rich tradition in the area of teaching language and literature (Hung, 2019; Dewi, 2019), is still in its infancy in translation studies, and has mainly been eclipsed by the mainstream linguistic-cultural perspectives. This perspective has attracted many researchers, thanks to whose efforts we now have a general idea of what translation competence is and what different constituent parts it enfolds (Göpferich, 2010, 2015; Jääskeläinen, 2011; Orazzco \& Hurtado Albir, 2002; PACTE, 2000, 2002, 2003, 2005, 2008). These studies also have a lot to say about how novice translators' performance differs from that of experts or professionals. (Dimitrova, 2005; Prassl, 2010).

Similarly, the didactic perspective to translation competence has inspired many writers including Campbell (1991), Chesterman (2000), Presas (2000) and Robinson (1997). However, as the insights these writers provide are not based on empirical methods, they lack the necessary scientific rigor. As Göpferich (2015) points out, what is specially lacking now in didactic area are scientific longitudinal studies with a focus on translation learners.

More developed delineations of translation competence acquisition, and the cognitive processes that it enfolds, may provide us with a comprehensive picture which could then be used to serve as signposts to guide the process of teaching translation, the pace of teaching, material development, and naturally, evaluation and assessment. However, studies as such, which are aimed at objectively picturing this intricate process are relatively rare and virtually, at the time of writing this report, non-existent in English-Persian language pair.

Thus, informed by more recent cognitive models and findings (Beeby et al., 2011; PACTE, 2003, 2005; Prassl, 2010), the present study aims to empirically picture the process of the development of translation competence in Iranian Persian-speaking translation learners. More specifically, we intend to map out the cognitive processes involved in problem-solving and provide a picture of the evolution of this fundamental aspect of translation competence through the course of translation programmes as offered in academia. The findings are hoped to add to our understanding of the mental processes that translation learners activate and the trajectory of the evolution of such processes at different stages of their training.

\section{LITERATURE REVIEW}

Traditionally, translation competence (TC) has been regarded as naturally emerging in the case of bilingualism; in other words, any bilingual person was seen to be able to translate a text across the languages they were competent at (Harris, 1977). This conception that all bilinguals can naturally be translators due to their linguistic ability has not been supported by empirical studies and, thus, has turned out to be a misconception (Lörscher 2012).

However, Wilss (1982, p. 58), from the vantage of a 'scientific' approach to translation problems and methods, sees TC as an inter-lingual super-competence which is based on a "comprehensive knowledge of the respective SL and TL, including the text pragmatic dimension, and consists of the ability to integrate the two monolingual competencies on a higher level". Further, Bell (1991, p. 43) defines TC in more reticent terms as "the knowledge and skills the translator must possess in order to carry out a translation". Similarly, Hurtado Albir (as cited in 
Orozco, 2002) defines TC simply as "the ability of knowing how to translate. From a more pragmatic view, PACTE (Process in the Acquisition of Translation Competence and Evaluation) group defines TC as "the underlying system of knowledge, abilities and attitudes required to be able to translate" (PACTE, 2002, p. 43).

A particularly comprehensive picture of TC and its constituent elements comes from the works of PACTE group (Beeby et al., 2011; PACTE, 2002, 2003, 2005, 2008)

PACTE (2003) lists five sub-competences for TC besides a sixth component labeled psycho-physiological component. These sub-competences include:

1) bilingual sub-competence, which features the ability to control interference and involves pragmatic, socio-linguistic, textual, grammatical and lexical knowledge in the two languages;

2) extra-linguistic sub-competence, including cultural, encyclopedic and subject knowledge;

3 ) knowledge about translation sub-competence, including knowledge about what translation is, how it functions and the knowledge related to professional practice;

4) instrumental sub-competence, including the ability to use sources of documentation and other technologies applied to translation practice;

5) strategic sub-competence, which has a fundamental role in controlling the whole translation process and is responsible for establishing inter-relations among the other sub-competences; it features the ability to solve translation problems, and

6) psycho-physiological components, including cognitive aspects like memory, perception, attention and emotion, and aspects like curiosity, rigor, perseverance, creativity, logical reasoning, analysis, etc.

The reason they separated this last component from others, which was actually a more recent development in the model as compared with the previous version, is that they believe psycho-physiological components are an integral part of any expertise and are not exclusively translational.

Another major concept, which has found its way into cognitive-oriented investigation of translation decision-making processes, is the concept of support. Alves (1996) and PACTE (2005) drew a distinction between internal and external support: "internal support refers to the retrieval of knowledge from the translator's long-term memory and external support to the consultation of external resources, such as dictionaries and parallel texts" (Alves, 1996; PACTE, 2005). According to Prassl (2010), many problem-solving and decision-making processes "require chains of these types of support before a solution can be found, and a solution always involves making a decision or choice, whether it is conscious or unconscious. It is these decisions or choices which, in the end, lead to the target text." (Prassl, 2010, P. 57-58)

Prassl (2010) integrates the idea of internal/external support with notions coming from psychology of decision-making, especially a four-partite categorisation of decision-making processes of routinised, stereotyped, reflected, and constructed processes, which were originally proposed by Jungermann and Fischer (2005).

Routinised processes occur whenever, "a single option is unconsciously retrieved in a pattern-match process, where the underlying evaluation takes place automatically." (Prassl, 2010, p. 61). In this process, the decision-maker matches the new situation to a pattern in his/her long term memory, with the given pattern being the result of developing the previous experiences into routine processes over time. 
Stereotyped decisions, however, are automatic, spontaneous, and mainly unconscious retrieval from long-term memory, where there is more than one option available (Jungermann \& Fischer, as cited in Prassl, 2010). This process, therefore, involves a minor evaluation in the form of verbal expressions referring to liking or disliking, wanting or not wanting a certain option, an evaluation that takes a little time, but is not guided by rational thinking (Prassl, 2010). Examples of this process include cases where a translator utters an equivalent but types a different one, or when he/she proposes a couple of TT equivalents and then types one of them without any evaluation (Prassl, 2010, p. 61).

Likewise, reflected processes may start with automatic retrieval, but options "have to be generated consciously and deliberately, using internal or external searches followed by evaluation" (Prassl, 2010, p. 62- 63). According to Prassl (2010), postponing decision-making for a later time, in the form of unfilled gaps in the target text (TT), can also indicate reflected processing.

Constructed processes, Prassl (2010) notes, occur when toward the end of the reflected decision-making processes the decision-maker has not yet found the answer and, thus, resorts to guessing in order to come to a conclusion. This may happen, when "the possibilities are elusive," the goals are not either clear or defined, cognitive involvement is high due to ill-structured problems, or because the evidence that helps a decision-maker opt for a possibility is ambiguous (Jungermann \& Fischer, as cited in Prassl, 2010, p. 63). Prassl attributes constructed decisionmaking to cases where a translator has ignored the translation requirements as specified in translation brief, or when he/she fails to comprehend part of the text due to lack of linguistic or extra-linguistic knowledge.

Still, another contributing concept in this study is the term translation problem. As far as the notion of translation problem is concerned, two approaches can be traced in the literature: linguistic and cognitive. In the linguistic perspective, translation problems are viewed as intersubjective and person-independent tasks, which even though the translator may learn to deal with effectively, they always remain problems (Nord 1997). According to Nord (1997), translation problems share three basic qualities: they are observable and, thus, can be measured; they can appear at any stage of translation process; and they are indicators of the translator's use of translation strategies. Yet, in the cognitive perspective, translation problems are viewed as the projections of cognitive endeavors on the part of translators. Here, problems may occur when the automatic processes fail to produce a preliminary TT, making the translator resort to translation strategies in a controlled manner in order to come up with an appropriate solution (Beeby, et al., 2011; Orozco, 2000).

Therefore, from the cognitive perspective, as opposed to the linguistic one, translation problems are not predetermined. They are dependent on the individual translator and are marked by certain indicators. Krings (as cited in Dimitrova, 2005), provides an inventory of useful translation problem indicators that can help operationalise the concept of translation problem as such. Some of the main indicators include: explicit or implicit problem identification by the translator, use of translation aids, leaving gaps in the TT, competing translation equivalents, changes in the TT, presence of underlining in the ST, explicit problematization, unfilled pauses (usually longer than 3 seconds), and paralinguistic (i.e., supra-segmental) elements.

According to Beeby et al. (2011) and Nord $(1997,2005)$, four main kinds of translation problems can be identified. They are:

1- linguistic, which are the result of lexico-syntactic contrast between ST-TT systems; 
2- textual, including coherence, cohesion, genre and style,

3- extra-linguistic, which are the result of the contrast between ST-TT cultures, and might include cultural, encyclopedic and subject-specific knowledge; and

4- pragmatic, which are the result of the contrast between ST-TT situations and may include inter-textuality, speech-acts, presuppositions, etc.

Given that our main concern in this study is to explore the cognitive processes involved in translational decision-making acts, the ideas presented above were employed to guide the process of data collection and analysis, as is further developed in the following section.

\section{METHODOLOGY}

The present study is a think-aloud study with qualitative data collection and data analysis techniques. Adopting PACTE's (2003) model of TC as its theoretical framework and building upon the findings of previous studies on the various decision-making processes and internal/external support types, this study intends to explore the development of TC among Iranian university students, using introspective verbal reports triangulated with target language translation outputs.

\section{PARTICIPANTS}

A group of 20 participants, 10 males and 10 females, were randomly selected from among the 97 students who took part in the early stages of the present research. The students were majoring in English Language and Translation at Birjand University, in the east of Iran. The participants were informed about the study and the informed consent was obtained. The students were divided into four groups labeled as G1, G3, G5 and G7 on the basis of the academic training they had received (the digits indicate the number of semesters of training they had received on English language and translation). Accordingly, the participants were assigned to three stages of translation competence development, namely pre-translational (G1), earlytranslational (G3) and translational (G5, G7).

TABLE 1. OPT standards for assessing language levels (Oxford University Press, 2001)

\begin{tabular}{cl}
\hline English Score & \multicolumn{1}{c}{ Level } \\
\hline $19 \sim 29$ & Elementary \\
$30 \sim 39$ & Low-Intermediate \\
$40 \sim 49$ & High-Intermediate \\
$50 \sim 54$ & Advanced \\
$55 \sim 60$ & Highly-Advanced \\
\hline
\end{tabular}

Also, in order to account for possible factors that might affect cognitive processing, the participants were selected on the basis of their age, English language knowledge, and outsidecampus translation experience. As it can be observed in Table 2 below, except for two, all the participants reported to have no off-campus translation experience, all of them fall within the minimal age limit for a student at the given levels, and are low-intermediate or above in English language knowledge. Except for G5 which, with an average OPT (Oxford Placement Test) of more than 40, qualifies itself as a high-intermediate group, the other three groups fall within a 
low-intermediate level of language knowledge (see Table 1 above, OPT standards for assessing language levels).

TABLE 2. Demographic information of the four groups of participants

\begin{tabular}{lccccc}
\hline Participant & Age & Gender & $\begin{array}{c}\text { Off-campus Tr. } \\
\text { Experience }\end{array}$ & $\begin{array}{c}\text { OPT } \\
\text { Score }\end{array}$ & Level \\
\hline M.B1 & 18 & $\mathrm{M}$ & 0 & 38 & Low-Intermediate \\
E.A1 & 18 & $\mathrm{M}$ & 0 & 37 & Low-intermediate \\
S.S1 & 19 & $\mathrm{~F}$ & 0 & 32 & Low-intermediate \\
A.Z1 & 18 & $\mathrm{M}$ & 0 & 45 & Low-intermediate \\
M.R1 & 19 & $\mathrm{~F}$ & 0 & 31 & Low-intermediate \\
M.M3 & 20 & $\mathrm{M}$ & 1 & 46 & High-intermediate \\
M.M.E3 & 19 & $\mathrm{~F}$ & 0 & 30 & Low-intermediate \\
E.K3 & 19 & $\mathrm{~F}$ & 0 & 42 & High-intermediate \\
D.D3 & 20 & $\mathrm{M}$ & 0 & 32 & Low-intermediate \\
E.A3 & 20 & $\mathrm{M}$ & 0 & 34 & Low-intermediate \\
M.R5 & 21 & $\mathrm{M}$ & 1 & 46 & High-intermediate \\
R.A5 & 21 & $\mathrm{M}$ & 0 & 41 & High-intermediate \\
Z.N5 & 20 & $\mathrm{~F}$ & 0 & 36 & Low-intermediate \\
B.M5 & 21 & $\mathrm{M}$ & 0 & 39 & Low-intermediate \\
M.M5 & 20 & $\mathrm{~F}$ & 0 & 49 & Advanced \\
F.N7 & 22 & $\mathrm{~F}$ & 0 & 32 & Low-intermediate \\
E.E7 & 21 & $\mathrm{M}$ & 0 & 44 & High-intermediate \\
F.T7 & 22 & $\mathrm{~F}$ & 0 & 30 & Low-intermediate \\
B.K7 & 21 & $\mathrm{~F}$ & 0 & 36 & Low-intermediate \\
B.M7 & 22 & $\mathrm{~F}$ & 0 & 34 & Low-intermediate \\
\hline G1 Average & 18.4 & - & 0 & 36.8 & Low-intermediate \\
G3 Average & 19.8 & - & 0 & 36.8 & Low-intermediate \\
G5 Average & 20.8 & - & 0 & 40.2 & High-intermediate \\
G7 Average & 21.8 & - & 0 & 35.2 & Low-intermediate \\
\hline
\end{tabular}

\section{INSTRUMENTS}

The instruments used in present research include a general information questionnaire, Oxford Placement Test (OPT), and a translation task. The questionnaire aimed at eliciting general information on participants' age, gender, off-campus translation experience, and translation or other relevant training they might have received. The OPT was administered in order to evaluate the source language (SL) knowledge level of the participants. The translation task involved direct translation of an English excerpt of less than 300 words on a popular science topic of 'winning friends'. The English excerpt was piloted on 25 students majoring in English Language to evaluate the difficulty level and also to locate the possible translation problems in it. The source text (ST) incorporated linguistic, extra-linguistic, textual, and pragmatic problems. The task also included a translation brief that involved important information on the ST and the function of translated text in the target language. The brief was in the participants' native language, i.e. Persian. The participants' concurrent verbalisations were recorded and transcribed into thinkaloud protocols for analysis purposes. 


\section{DATA COLLECTION}

In this phase of the study, the participants were initially briefed on how to think aloud and then an about twenty-minute training session was administered in which the participants practiced thinking aloud while translating a short English text into Persian. Meanwhile, the participants' performance was observed and necessary feedback was given in order to minimise the possibility of disruptions during the actual phase of the experiment. Enough care was exercised to avoid directing the participants thought processes or giving them specific directions on how to think aloud in order to account for the free play of individual and idiosyncratic patterns of thought processes. Ecological validity of the experiment was established by keeping the physical presence and interruption of the researchers to a minimum and by availing the participants with any electronic or non-electronic sources of documentation they preferred to use. Employing voice recorders instead of video cameras was also part of our attempt to maintain ecological validity. Many participants would not feel at home when they realise they are being watched or filmed, and this would seriously damage the validity of the findings. There was no verbal communication between the researchers and the participants during the study so as to avoid interfering with the thought processes of the participants. The students were given hints in case their voices started to fade or they stopped verbalizing their thoughts. The introspective verbalisations of the participants were recorded and then transcribed into think-aloud protocols (TAPs). The whole process of thought verbalisation was in the participants' native language, i.e., Persian.

\section{DATA ANALYSIS}

The obtained TAPs were codified on the basis of the categorisation of translation problems provided by Beeby et al. (2011) and Nord (1997), the classification of decision-making processes provided by Jungermann and Fischer (2005), and the concept of internal/external support as proposed by Alves (1996). We employed the concept of 'textual node' to refer to those parts of the ST that incorporate one or more than one potential translation problems. The identification of textual nodes was done inter-subjectively (with the help of two expert judges), and also on the basis of the findings of pilot study supplemented by the performance of the participants in the main phase of the study. We identified some 18 textual nodes in the English ST which guided the process of codification and analysis. These textual nodes produced 21 translation problems: 12 linguistic, 3 extra-linguistic, 3 textual and 3 pragmatic problems. To maximise objectivity in the codification process, the thought processes of the individual participants, on any given translation problem (or textual node), were meticulously considered with reference to both the TAP and the translators' final translation outputs submitted in handwriting. Here, the participants' verbalisations alongside with supra-segmental elements such as tone, pitch, and rhythm, temporal variables including pauses, hesitations, and repetitions, and also self-corrections and modifications were carefully considered. The thought processes were, then, carefully described and presented in certain tables. The descriptions thus obtained were subsequently mapped onto the delineations of decision-making and support types as proposed by Jungermann and Fischer (2005) and Alves (1996). By this means, the performance of each individual participant on each translation problem was attributed to a certain decision-making type and type of support. To maximise objectivity, codification was verified by two expert judges.

We also analysed the translation outputs for acceptability, although other concepts like translation intelligibility can also be found in the literature to have been used for the same 
purpose (Norwati, et al., 2017). For the purpose of this study, following Beeby et al. (2011, p. 42), the acceptability of the solutions was established by reference to answers to the following three questions: does the translation solution effectively communicate the meaning of the source text?; (b) does it effectively communicate the function of the translation (with reference to the translation brief, the target readers' expectations and genre conventions, etc.)?; and (c) does it make use of appropriate language? To build more objectivity into the evaluation job, two expert judges, both university teachers and with more than 15 years of professional experience, judged the solutions on the basis of a rubric designed with the above three questions. Only those solutions that received three 'Yes's' on the three questions in the rubric were evaluated as acceptable. The final results were tabulated and the obtained numeric data was transferred to Microsoft Excel to help see if they show any pattern of evolution.

\section{FINDINGS AND DISCUSSION}

In this section, the performance of the four groups of participants on the task, alongside with the cognitive processes underlying their decision-making acts will be explored, discussed, and supporting examples will be provided. The findings will then be put together in search for a pattern of TC development.

\section{PRE-TRANSLATIONAL GROUP (G1)}

Table 3 shows the overall performance of the participants in G1 on the specified linguistic, extralinguistic, textual and pragmatic problems. In order to account for the participants' knowledge of grammar, we divided linguistic problems into lexical and syntactic/lexico-syntactic problems. Also, the terms Solved and Unsolved in the table refer to acceptable and unacceptable solutions respectively.

TABLE 3. Overall performance of G1 on translation problems

\begin{tabular}{lccccccccccc}
\hline $\begin{array}{l}\text { Problem } \\
\text { Type }\end{array}$ & $\begin{array}{c}\text { Total } \\
\text { No. }\end{array}$ & $\begin{array}{c}\text { Solved } \\
\text { No. }\end{array}$ & $\begin{array}{c}\text { Solved } \\
\%\end{array}$ & $\begin{array}{c}\text { Unsolved } \\
\text { No. }\end{array}$ & $\begin{array}{c}\text { Unsolved } \\
\%\end{array}$ & $\begin{array}{c}\text { Rt. } \\
\text { No. }\end{array}$ & $\begin{array}{c}\text { St. } \\
\text { No. }\end{array}$ & $\begin{array}{c}\text { Rf. } \\
\text { No. }\end{array}$ & $\begin{array}{c}\text { Con. } \\
\text { No. }\end{array}$ & $\begin{array}{c}\text { Int. } \\
\text { Sup. } \\
\text { No. }\end{array}$ & $\begin{array}{c}\text { Ext. } \\
\text { Sup. } \\
\text { No. }\end{array}$ \\
\hline $\begin{array}{l}\text { Lexical } \\
\text { Syntatic/lexico- }\end{array}$ & 20 & 7 & 35 & 13 & 65 & 11 & 5 & 4 & 0 & 16 & 4 \\
syn.* & 13 & 32 & 27 & 68 & 21 & 13 & 4 & 0 & 34 & 4 \\
Ext. ling.** & 15 & 3 & 20 & 12 & 80 & 5 & 1 & 7 & 0 & 6 & 7 \\
Textual*** & 15 & 3 & 20 & 12 & 80 & 5 & 2 & 5 & 0 & 7 & 5 \\
Pragmatic & 15 & 2 & 13 & 13 & 87 & 10 & 1 & 4 & 0 & 11 & 4 \\
\hline $\begin{array}{l}\text { Total } \\
\text { Percentage }\end{array}$ & 105 & 28 & - & 77 & - & 52 & 22 & 24 & 0 & 74 & 24 \\
*2 omissions & 100 & 26.5 & - & 73.5 & - & 49 & 21 & 23 & 0 & 70 & 23 \\
$* * 2$ omissions & & & & & & & & & & & \\
$* * * 3$ omissions & & & & & & & & & & &
\end{tabular}

Our findings revealed that G1 members employed both internal and external support resources and resorted to routinised (Rt.), stereotyped (St.) and reflected (Rf.) decision-making processes (MR1 showed only internal-support and just Rt. and St. processes). However, no constructed (Con.) processes were observed in any of the members of this group. The rate of the acceptability of the solutions in G1 varied slightly from five to maximum seven out the total of 
21 solutions, which boils down to an average of merely about $26 \%$ acceptable solutions. About $73 \%$ of the solutions were unacceptable.

The same homogeneity was observed in the decision-making processes G1 members exhibited. About $50 \%$ of all the solutions, whether successful or not, were arrived at through the unconscious process of Rt. This signals an over-dominance of routinised processes in this group. However, with an average of $23 \%$, Rf. processes are relatively scarce. As a corollary, the rate of internal-support is high; $70 \%$ of all the decisions are internal support and only $23 \%$ of them are devoted to external support.

With an average of seven percent, G1 enjoys the highest rate of omission. As can be seen from Table 3, these omissions belong to syntactic, extra-linguistic and textual problems. Given the high percentage of internal support and Rt./St. processes, and with regard to higher difficulty level of extra-linguistic and textual problems, it seems that pre-translational participants resorted to omission as a kind of avoidance strategy. They tried to solve the aforementioned problems without directly encountering them.

Consider the following examples from MR1: (English back-translation has been provided in square brackets.)

"...with his beautiful eyes staring steadfastly at the path, and as soon as he heard my voice or saw me swinging my dinner pail through the buck brush, he was off like a shot, racing breathlessly up the hill to greet me with leaps of joy and barks of sheer ecstasy."

[with his beautiful eyes stared at the path, and as soon as he heard my voice or saw me having dinner, he was shut silent like.... . raced breathlessly up the hill to meet me]

(The parts of the English ST which are bold-typed signify translation problems.)

A comparison of the ST with the TT and its English back translation reveals interesting information. The translator decided to avoid all the problem areas which either needed checking dictionaries or consulting encyclopedic sources; phrases like 'steadfastly', 'sheer ecstasy', 'dinner pail' and 'buck brush'. To translate 'swinging dinner pail', she went through the following thought process (the parts in italics denote the description of the translator's thought processes as extracted from the TAP): First thinks of 'taking food', pauses, then modifies it into 'eating dinner', wonders what 'swing' and 'dinner pail' mean, reads the ST segment, utters the TT, pauses, reads the ST, utters the TT, pauses, reads the ST, utters the TT, writes the TT. This cognitive processing indicates that she did not know the meaning of these words and that she was trying to work them out through some internal sources. In the face of 'buck brush', she reads the ST, pauses, reads the ST again in a question tone and with a rising intonation, pauses, finishes her translation, and thus omitted it from her translation all together.

Another thing that we noticed is that G1 participants resorted to external sources quite scarcely and mostly relied on their internal sources in the face of translation problems. Besides this, we observed an obvious inclination toward overusing bilingual English to Persian dictionaries for comprehension and translation purposes. E.A1 and S.S1 were the only of the five participants in this group who made use of monolingual dictionaries too. Other participants only relied merely on their bilingual dictionaries to solve their problems. In addition, G1 made extensive use of dialogic Persian in their outputs which, given the genre of the ST (i.e. popular science), was considered to be stylistically wrong. Also, there were some cases where students in 
G1 generated Persian equivalents for corresponding ST segments, but showed a lack of ability to select only one from the produced options.

\section{EARLY TRANSLATIONAL GROUP (G3)}

Table 4 demonstrates the performance of the early-translational group G3 on translation problems.

TABLE 4. Overall performance of G3 on translation problems

\begin{tabular}{lccccccccccc}
\hline $\begin{array}{l}\text { Problem } \\
\text { Type }\end{array}$ & $\begin{array}{c}\text { Total } \\
\text { No. }\end{array}$ & $\begin{array}{c}\text { Solved } \\
\text { No. }\end{array}$ & $\begin{array}{c}\text { Solved } \\
\%\end{array}$ & $\begin{array}{c}\text { Unsolved } \\
\text { No. }\end{array}$ & $\begin{array}{c}\text { Unsolved } \\
\%\end{array}$ & $\begin{array}{c}\text { Rt. } \\
\text { No. }\end{array}$ & $\begin{array}{c}\text { St. } \\
\text { No. }\end{array}$ & $\begin{array}{c}\text { Rf. } \\
\text { No. }\end{array}$ & $\begin{array}{c}\text { Con. } \\
\text { No. }\end{array}$ & $\begin{array}{c}\text { Int. } \\
\text { Sup. } \\
\text { No. }\end{array}$ & $\begin{array}{c}\text { Ext. } \\
\text { Sup. } \\
\text { No. }\end{array}$ \\
\hline $\begin{array}{l}\text { Lexical } \\
\text { Syntatic/lexico- }\end{array}$ & 20 & 11 & 55 & 9 & 45 & 11 & 1 & 8 & 0 & 13 & 7 \\
syn. & 17 & 42 & 23 & 58 & 14 & 5 & 18 & 3 & 22 & 18 \\
Ext. ling. & 15 & 1 & 7 & 14 & 93 & 2 & 2 & 5 & 6 & 6 & 9 \\
Textual & 15 & 9 & 60 & 6 & 40 & 3 & 5 & 4 & 3 & 9 & 6 \\
Pragmatic & 15 & 3 & 20 & 12 & 80 & 4 & 2 & 5 & 4 & 9 & 6 \\
\hline $\begin{array}{l}\text { Total } \\
\text { Percentage }\end{array}$ & 105 & 41 & - & 64 & - & 34 & 15 & 40 & 16 & 59 & 46 \\
\hline
\end{tabular}

Our findings revealed that G3 manifested an improvement on the distribution of cognitive resourcing and decision-making processes. Here, we find the full array of decision-making processes at work; Rt., St., Rf., and even Con. decision-making processes all have their share. Yet, against G1, here the Rf. processes, with an average of a little less than $40 \%$, predominate. Then come Rt. processes with a little more than 30\%, and finally Con. and St. with about $15 \%$. Internal-support and external-support are also more equally distributed: $56 \%$ for internal and $44 \%$ for external-support cognitive resources. This is while, this ratio was $70 \%$ to about $20 \%$ in the case of G1.

A further development that was witnessed in G3 was lack of undue omissions. Let us illustrate the point with an example from M.M3.

"...as soon as he heard my voice or saw me swinging my dinner pail through the buck brush, he was off like a shot..."

[...as soon as he heard my voice or saw me swinging my dinner dish he was off like an arrow from a bow...]

As can be seen, the translator decided not to render the phrase 'through the buck brush'. But when we referred to the TAP we came to this description of the thinking process: reads $S T$, wonders, "What does 'buck brush' mean?" looks up the words 'buck' and 'brush' in a dictionary, repeats the ST segment again, reads the whole ST sentence from the beginning, pauses for 7 seconds, reads the Persian TT sentence, pauses for 3 more seconds, and produces the final TT without translating the ST segment. This thinking process reveals that the translator opted for omitting the translation problem after considerable internal and external-support thought processes. It seems that after conscious reflection on the problem, which is signalled through his verbal comment and dictionary checking, he concludes that this problem can be justifiably deleted without doing any harm to the overall meaning and intention of the text. This is while, 
the translators in G1 frequently opted for omissions simply because they found the ST hard to comprehend or difficult to translate.

In addition, the analysis of the TAPs and TTs revealed that at this level, learners are still ignorant of the significance of context and the role of revision in translation. In most TAPs obtained from this group (4 out 5), it was obvious that the unit of translation is mainly clause or, when it comes to more complicated parts of the text, even word. None of the participants in this group read the translation brief or the whole text before embarking on the task of translating the text. As for final revision, in four out of the five participants in this group, no records were found of doing any final revisions. However, an overall examination of the performance of G3 revealed that the style of writing has greatly improved in favor of standard writing style in target language (TL). Let us consider another example taken from E.A3.

"When you get within ten feet of him, he will begin to wag his tail. If you stop and pat him, he will almost jump out of his skin to show you how much he likes you."

[When we get within less than three meters of him, he will start to wave to us. If we stop and strike him on the back with our hand, he will be shocked and will lose his self-control to show how much he likes us.]

The thinking process of E.A3 for translating 'wag his tail' is as follows: reads ST, looks up the words 'wag' and 'tail' in a dictionary, repeats ST segment, pauses, repeats ST again, pauses again, reads the previous TT segment, utters TT, pauses long (i.e. more than 10 seconds), repeats his $T T$, writes his $T T$. The fact that he paused and repeated the TT he had uttered before writing it down shows that he was not sure about the final solution, and that is why it is classified as a constructed solution (Con). The same arduous process has been recorded for translating 'pat him' and 'jump out of his skin': reads ST, pauses for a long time, repeats the ST segment, reads the whole ST sentence to the end, repeats the ST segment, reads the preceding TT sentence, utter his TT, writes his TT. That the translator keeps going back and forth along the ST and TT sentence and keeps repeating the ST segment (i.e. the translation problem) unfolds his laborious cognitive endeavors to create cohesion, or more accurately intra-sentential cohesion, between the previous part of his translation and the new translation problem. The interesting part of the story is that extensive use of dictionary does not help him get at the right answer, either. From the long pauses that intercede, we can understand that the translator reflected on the solutions that the external sources provided, and evaluated them on the basis of his own preconceived notions of the general theme of the ST, but since he had not read the text and comprehended it fully before embarking on the translation task, this reflection and conscious evaluation turned out to be counter-productive, simply because it had been based on an ill-judged conception of the ST topic.

This, as well as many other examples we found, indicates that deep down, the learner still assumes that translation is context-free, that it must be clause by clause at pace, with no prereading activity necessary, and that cohesion is defined at intra-sentential level. To fill the gap of the context, the learner brings his/her preconceived notions, which are absolutely unguided by the topic of the text, into play and, at the same time, shows a sense of distrust towards external sources; he/she rejects the solutions offered by the dictionary in favor his personal conception as to the general topic of the text. All these contradictions gathered in one place indicate that the learner has some sort of translation knowledge. This knowledge, however, is not well-organised; it is ambiguous and full of contradictions: you cannot fully trust a dictionary because dictionaries 
do not know anything about your text and your context, and contexts are not important, you don't have to read the whole text to get a general idea of what a text is about; individual sentences will do!

\section{TRANSLATIONAL GROUP (G5 AND G7)}

Table 5 demonstrates that the cognitive processes of decision-making in G5 have been distributed along the Rt., St. and Rf. processes, and include both internal and external support resourcing. If we compare the overall performance of G5 with G3, it becomes clear that the rate of acceptability has improved from $39 \%$ in G3 to more than $46 \%$ in G5. Except for Rt. Processes, which have almost remained unchanged, St. and Rf. processes show a steady change of eight and 10 percent increase respectively. Con. Processes, however, show a sharp decline: no Con. processes were recorded in the TAPs.

TABLE 5. Overall performance of G5 on translation problems

\begin{tabular}{llllllllllll}
\hline $\begin{array}{l}\text { Problem } \\
\text { Type }\end{array}$ & $\begin{array}{c}\text { Total } \\
\text { No. }\end{array}$ & $\begin{array}{c}\text { Solved } \\
\text { No. }\end{array}$ & $\begin{array}{c}\text { Solved } \\
\%\end{array}$ & $\begin{array}{c}\text { Unsolved } \\
\text { No. }\end{array}$ & $\begin{array}{c}\text { Unsolved } \\
\%\end{array}$ & $\begin{array}{c}\text { Rt. } \\
\text { No. }\end{array}$ & $\begin{array}{c}\text { St. } \\
\text { No. }\end{array}$ & $\begin{array}{c}\text { Rf. } \\
\text { No. }\end{array}$ & $\begin{array}{c}\text { Con. } \\
\text { No. }\end{array}$ & $\begin{array}{c}\text { Int. } \\
\text { Sup. } \\
\text { No. }\end{array}$ & $\begin{array}{c}\text { Ext. } \\
\text { Sup. } \\
\text { No. }\end{array}$ \\
\hline $\begin{array}{l}\text { Lexical } \\
\text { Syntatic/lexico- }\end{array}$ & 20 & 11 & 55 & 9 & 45 & 7 & 5 & 8 & 0 & 11 & 9 \\
syn. & 23 & 57 & 17 & 42 & 16 & 9 & 15 & 0 & 26 & 14 \\
Ext. ling. & 15 & 4 & 27 & 11 & 73 & 3 & 4 & 8 & 0 & 10 & 5 \\
Textual & 15 & 5 & 33 & 10 & 67 & 3 & 2 & 10 & 0 & 10 & 5 \\
Pragmatic & 15 & 6 & 40 & 9 & 60 & 6 & 4 & 5 & 0 & 11 & 4 \\
\hline $\begin{array}{l}\text { Total } \\
\text { Percentage }\end{array}$ & 105 & 49 & - & 56 & - & 35 & 24 & 46 & 0 & 68 & 37 \\
\hline
\end{tabular}

The increase in St. and Rf. processes indicate a growth in conscious reflection in the face of translation problems. However, contrary to this increase, the external support resourcing has decreased. This shows that the increase in conscious reflection does not necessarily mean an increase in external support resourcing. In G5, the increase in conscious reflection has accompanied an increase in internal-support resourcing from $56 \%$ in G3 to $65 \%$ in G5. This means that in G5, reliance on internal support resources (i.e. long-term memory) for consciously solving translation problems has increased. In simpler language, G5 used external resources less often but reflected on its solutions more often than the immediately preceding group G3.

Let us explore this latter issue more elaborately. Here, three variables are at work: SL knowledge, cognitive resourcing (i.e. internal vs. external support) and conscious reflection. The relationship between language knowledge and cognitive resourcing seems to be clear: increase in SL knowledge means increased internal-support cognitive resourcing and, consequently, decreased external support. However, the increase in internal support led not to an increase in automatised and routinised problem-solving processes but, rather, decreased them. If the increase in internal-support resourcing could be explained in the light of higher language knowledge scores that the G5 participants obtained, the explanation for the increase in conscious reflections, or rather, the decrease in automatised unconscious processing, should be sought in the translation training the participants had received. In other words, although the increase in SL ability increased the chance of resorting to internal-support resources, translation training increased the volume of conscious reflections. This is an important finding that, with regard to the limitations of the present study, cannot be generalised. However, it can demonstrate the 
relationship between translation training and the cognitive processes underlying decision-making acts: Increased training may lead to increased internal-support processes and, at the same time, increased conscious reflections.

Yet, from another perspective, G5 showed a decent performance on generating translation solutions; however, with regard to act of selecting one solution, the TAPs showed numerous cases where the translator wondered which solution to adopt; most of them culminated in TT products teeming with parenthesized contents offering the reader as many options as the translator could have worked out. In the TT that M.M5 produced, for instance, we found twelve cases where the translator provided two or even three solutions for a single problem.

Table 6 demonstrates the general performance of G7 as a whole in the present study.

TABLE 6. Overall performance of G7 on translation problems

\begin{tabular}{|c|c|c|c|c|c|c|c|c|c|c|c|}
\hline $\begin{array}{l}\text { Problem } \\
\text { Type }\end{array}$ & $\begin{array}{c}\text { Total } \\
\text { No. }\end{array}$ & $\begin{array}{c}\text { Solved } \\
\text { No. }\end{array}$ & $\begin{array}{c}\text { Solved } \\
\%\end{array}$ & $\begin{array}{c}\text { Unsolved } \\
\text { No. }\end{array}$ & $\begin{array}{c}\text { Unsolved } \\
\%\end{array}$ & $\begin{array}{l}\text { Rt. } \\
\text { No. }\end{array}$ & $\begin{array}{l}\text { St. } \\
\text { No. }\end{array}$ & $\begin{array}{l}\text { Rf. } \\
\text { No. }\end{array}$ & $\begin{array}{l}\text { Con. } \\
\text { No. }\end{array}$ & $\begin{array}{c}\text { Int. } \\
\text { Sup. } \\
\text { No. }\end{array}$ & $\begin{array}{c}\text { Ext. } \\
\text { Sup. } \\
\text { No. }\end{array}$ \\
\hline Lexical & 20 & 8 & 40 & 12 & 60 & 6 & 4 & 10 & 0 & 15 & 5 \\
\hline $\begin{array}{l}\text { Syntatic/lexico- } \\
\text { syn. }\end{array}$ & 40 & 19 & 47 & 21 & 53 & 7 & 11 & 21 & 1 & 29 & 11 \\
\hline Ext. ling. & 15 & 4 & 27 & 11 & 73 & 4 & 2 & 9 & 0 & 8 & 7 \\
\hline Textual* & 15 & 5 & 33 & 10 & 67 & 4 & 1 & 9 & 0 & 7 & 7 \\
\hline Pragmatic & 15 & 9 & 60 & 6 & 40 & 3 & 3 & 9 & 0 & 7 & 8 \\
\hline Total & 105 & 43 & - & 62 & - & 24 & 21 & 58 & 1 & 66 & 38 \\
\hline Percentage & 100 & 41 & - & 59 & - & 23 & 20 & 55 & 1 & 63 & 36 \\
\hline
\end{tabular}

*1 omission

As can be seen from Table 6, G7 employed Rt. St. and Rf. thinking processes, but almost no Con. processes were observed. Rf. processes, with an average of $55 \%$ of all the solutions, have by far the biggest share of decision-making processes. This is also the biggest ratio of Rf. processes among all the four groups present in this study. With regard to cognitive resourcing, these decision-making processes are divided into 63\% internal support and 36\% external support processes, which is very much like the preceding group G5. When we put the high percentage of internal support resourcing beside the unprecedented rate of $\mathrm{Rf}$. solutions, it provides us with further support to the claim that increased exposure to translation training entails increased reliance on internal support resources (i.e. long-term memory) for consciously solving translation problems.

The overall acceptability rate of $\mathrm{G} 7$ shows that only $41 \%$ of their solutions were judged acceptable and the remaining $59 \%$ of them were evaluated as unacceptable, which reveals about $5 \%$ underperformance as compared with the immediate lower group G5.

\section{PATTERN OF TC DEVELOPMENT}

Figure 1 presents a summation of the statistics provided in the previous tables. When we put these statistics together, the general picture of the evolution of cognitive processes involved in translation and the acceptability rate of the solutions provided thereby, starts to take shape. The statistics for translational group is the average of the performance of G5 and G7.

This figure clearly illustrates what happens to different cognitive processes involved in translation problem solving with the increasing stage of translation competence, or rather, with the increased exposure to translation courses offered at university. The figure reveals increased 
chances of coming to successful solutions and the decreased unacceptable solutions with the increasing translation competence development, which seems to be quite natural. The odd thing, however, rests in the evolution of the performance of these three groups on decision-making processes.

The Figure 1 below demonstrates the evolution of evaluative (St./Rf.) and non-evaluative (Rt.) decision-making processes across the four groups.

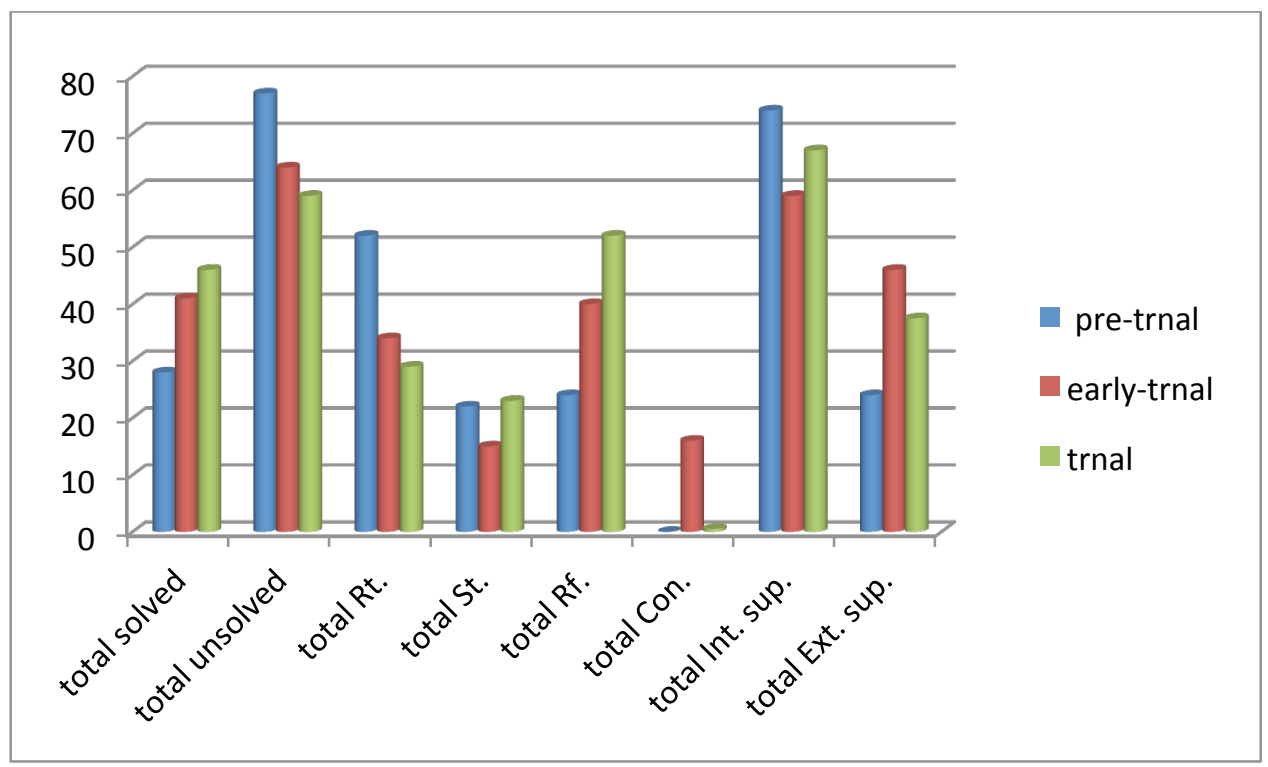

FIGURE 1. The general picture of the evolution of cognitive processes and the success rate of solutions among pre-translational, early-translational and translational groups

Strikingly, as the Figure 1 shows, with increasing exposure to translation training, the evaluative decision-making processes of Rf. increase and the non-evaluative processes of Rt. decrease. In other words, participants at pre-translational and early translational stages of translation competence development exhibited more non-evaluative and unconscious (and therefore automatised) processes than the participants at the translational stage. This last finding challenges the generally held conception that improved translation competence equals increasing automatisation of the translation process. This is to say that far from being at the service of fostering automatisation of the translation process, the translation programmes tend to boost students' evaluative reflections on the translation process. With regard to the relatively slow pace of conscious processes, as compared with the automatised ones, and given the qualifications for translation market that seriously require automatised and fast processing, these findings show that translation training as such falls short of preparing the learners for translation market. 


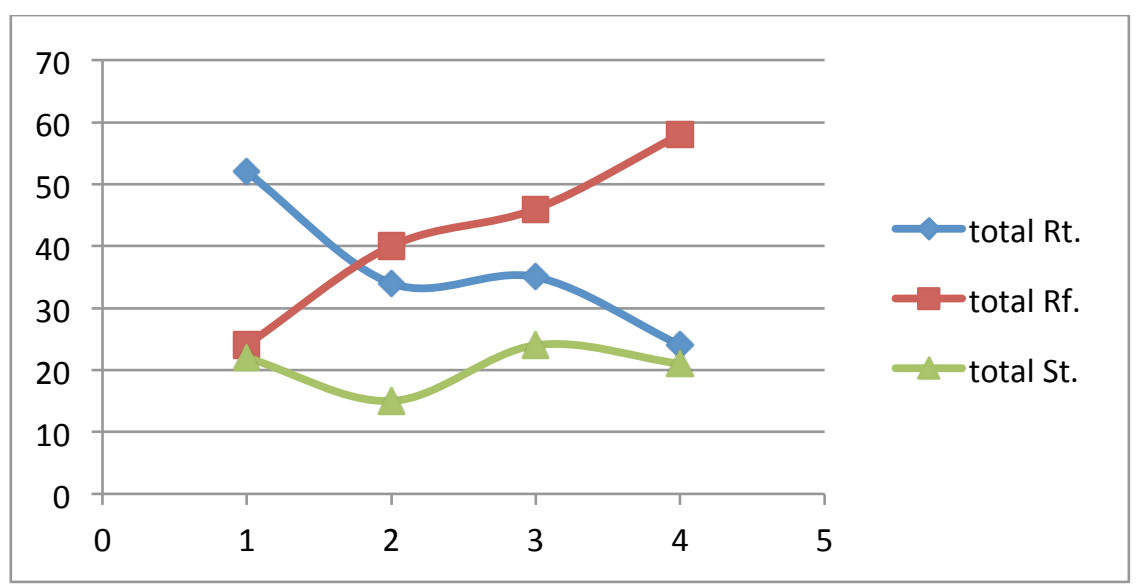

FIGURE 2. The pattern of evolution of Rt. St. and Rf. decision-making processes; the digits 1, 2, 3, and 4 on Y-axis stand for the four groups of G1, G3, G5 and G7 respectively. Note the downward trend of Rt. decision-making processes and the upward trend of Rf. processes

\section{CONCLUSION}

In this report, we focused on picturing the development of translation competence by investigating the cognitive processes underlying translation learners' decision-making processes. We also tried to map out the trajectory of the evolution of these cognitive processes as the learners are exposed to more and more translation courses. The findings indicated that in contrast to an incremental pattern of the development of acceptability rate of the translation solutions (i.e. products), such pattern of evolution does not hold up on the translation process axis. The findings also showed that at different stages of translation competence, learners hold various notions of the translation practice. A student at a pre-translational-stage holds a substantially source-text-oriented concept of translation; to him/her translation equals comprehension of the source text. The fact that this group enjoyed the highest rate of unconscious, routinised decisionmaking processes, that they showed the highest rate of undue omissions, and that they mostly resorted to the stylistically wrong dialogic Persian in their translation product support this claim. At an early-translational stage, however, this basically ST-oriented and embryonic notion of translation takes up more flesh. Learners have some idea of what translation is and how it should be conducted, but this knowledge is not systematised yet; it is at its infancy and full of contradictions and uncertainties. At a translational stage, the notion of translation matures. It achieves more balance in the orientation towards source and target languages as compared with the previous stages, and the students are increasingly obsessed with their target texts (the relatively increasing stereotyped and the numerous parenthesized alternative solutions found in this group besides the increasing rate of the acceptability of solutions support this claim).

As for decision-making processes, students activate different arrays of decision-making processes and internal/external support types at different stages of TC development. The evolutionary trajectory of these processes, however, is in favor of increased consciously evaluative and reflective decision-making processes, and the decreased intuitive and automatised thinking processes. That is to say, although from a product-oriented perspective translation programmes seem to be successful in enhancing the general acceptability of the learners' translation products, from a process-oriented perspective, these programmes do not seem to prepare the learners for translation market requirements. The findings further suggest that 
learning translation has different cognitive requirements at pre-translational, early-translational and translational stages of $\mathrm{TC}$ development. This is to say that translation pedagogy ought to account for the differences in cognitive properties of learners at different stages of TC development in designing curriculum and developing materials.

\section{REFERENCES}

Alves, F. (1996). Veio-me um 'click' na cabeça: The theoretical foundations and the design of a psycholinguistically oriented, empirical investigation on German-Portuguese translation processes. Meta: Translator's Journal. 4l(1), 33-44.

Beeby, A., Fernández, M., Fox, O., Hurtado Albir, A., Kuznik, A., Neunzig, W. \& Wimmer, S. (2011). Results of the validation of the PACTE Translation Competence model: Translation project and dynamic translation index. In S. O’Brien, (Ed.), Cognitive Explorations of Translation (pp. 30-53). London \& New York: Bloomsbury.

Bell, R. T. (1998). Psycholinguistic/cognitive approaches. In M. Baker (Ed.), Routledge encyclopedia of translation studies (pp. 185-190). London and New York: Routledge.

Campbell, S. (1991). Towards a model of translation competence. Meta: Journal des traducteurs/Meta: Translators' Journal. 36(2-3), 329-343. doi: 10.7202/002190ar

Chesterman, A. (2000). Teaching strategies for emancipatory translation. In C. Schäffner \& B. Adab (Eds.), Developing Translation Competence (pp. 77-90). Amsterdam/Philadelphia: John Benjamins Publishing Company.

Dewi, N. (2019). Cognition, Conscience, and Creativity: Multimedia-Based Literature Teaching for Pre-Service Teachers in Indonesia. 3L: Language, Linguistics, Literature ${ }^{\circledR}$. 25(2). doi: 10.17576/3L-2019-2502-07

Dimitrova, B. E. (2005). Expertise and Explicitation in the Translation Process (Vol. 64). Amsterdam/Philadelphia: John Benjamins Publishing Company.

Göpferich, S. (2015). Translation competence: Explaining development and stagnation from a dynamic systems perspective. In M. Ehrensberger-Dow, S. Göpferich, \& S. O'Brien, (Eds.), Interdisciplinarity in translation and interpreting process research (Vol. 72, pp. 63-78). Amsterdam/Philadelphia: John Benjamins Publishing Company.

Göpferich, S. (2010). Data documentation and data accessibility in translation process research. The Translator. 16(1), 93-124. doi: 10.1080/13556509.2010.10799295

Harris, B. (1977). The importance of natural translation. Working Papers on Bilingualism, No. 12. 96-114.

Hung, B. P. (2019). A Cognitive Linguistic Approach to Teaching English Idioms to EFL Students: Experimental Results. 3L: Language, Linguistics, Literature ${ }^{\circledR}$. 25(2). doi: 10.17576/3L-2019-2502-09

Hurtado Albir, A. (Ed.). (2017). Researching translation competence by PACTE group (Vol. 127). Amsterdam/Philadelphia: John Benjamins Publishing Company.

Jäskeläinen, R. (2011). Studying the Translation Process. In K. Malmkjaer \& K. Windle (Eds.), The Oxford handbook of translation studies (pp. 123-135). Oxford: Oxford University Press.

Jungermann, H., \& Fischer, K. (2005). Die Psychologie der Entscheidung: Eine Einfuhrung [Psychology of decision: An introduction]. Munchen: Elsevier.

Lörscher, W. (2012). Bilingualism and Translation Competence. SYNAPS-A Journal of Professional Communication, 27, 3-15. Retrieved 15 June 2017, from: https://brage.bibsys.no/xmlui/bitstream/handle/11250/2393971/Lorscher_27.pdf?sequence=1. 14.9.2016

Nord, C. (1997). A Functional Typology of Translation. Amsterdam/Philadelphia: John Benjamins.

Nord, C. (2005). Text analysis in translation: Theory, methodology, and didactic application of a model for translation-oriented text analysis (No. 94). Rodopi.

Orozco, M., and A. H. Albir (2002). Measuring translation competence acquisition. Meta: Translators' Journal. 47(3), 375-402. doi: 10.7202/008022ar

Orozco, M. (2000). Building a measuring instrument for the acquisition of translation competence in trainee translators. In C. Schäffner and B. Adab (Eds.). Developing translation competence. (John Benjamins Library Vol. 38, pp. 199-214). Amsterdam/Philadelphia: John Benjamins Publishing Company.

Oxford University Press (2001). Quick placement test: Paper and pen test, user manual.

PACTE Group. (2000). Acquiring translation competence: Hypotheses and Methodological Problems in a Research Project. In A. Beeby, D. Ensinger \& M. Presas (Eds.), Investigating translation (pp. 99-106). Amsterdam: John Benjamins. 
PACTE Group. (2002). Exploratory tests in a study of translation competence. Conference Interpretation and Translation. 4(2), 41-69.

PACTE Group. (2003). Building a translation competence model. PACTE, Universitat Autonoma de Barcelona. N.P. Retrieved 1 March 2016, from: http:/grupsderecerca.uab.cat/pacte/sites/grupsderecerca.uab.cat.pacte/files/2003_PACTE_Benjamins_0.pdf

PACTE Group. (2005). Investigating translation competence: conceptual and methodological issues. Meta: Translator's Journal. 50(2), 609-619. doi: 10.7202/011004ar

PACTE Group. (2008). First results of a translation competence experiment: knowledge of translation and efficacy of the translation process. Translator and Interpreter Training: Issues, Methods and Debates. 104-126. doi: 10.7202/011004ar

PACTE Group. (2009). Results of the validation of the PACTE translation competence model: acceptability and decision making. Across Languages and Cultures. 10(2), 207-30. doi: 10.1556/Acr.10.2009.2.3

Prassl, F. (2010). Translators' decision-making processes in research and knowledge integration. Copenhagen Studies in Language. 39, 57-81.

Presas, M. (2000). Bilingual Competence and Translation Competence. Amsterdam/Philadelphia: Benjamins Translation Library.

Pym, A. (2003). Redefining translation competence in an electronic age. In defense of a minimalist approach. Meta: journal des traducteurs/Meta: Translators' Journal.48(4), 481-497. doi: 10.7202/008533ar

Robinson, D. (1997). Becoming a Translator: An Accelerated Course. London \& New York: Routledge.

Schäffner, C. \& Adab, B. (Eds.). (2000). Developing translation competence (Vol. 38). Amsterdam/Philadelphia: John Benjamins.

Wilss, W. (1982). The science of translation: problems and methods (Vol. 180). John Benjamins Publishing Company.

Yusof, N. M., Darus, S. \& Ab Aziz, M. J. (2017). Evaluating Intelligibility in Human Translation and Machine Translation. 3L: Language, Linguistics, Literature ${ }^{\circledR}$. 23(4). doi: 10.17576/3L-2017-2304-19 